\title{
Induction of larval attachment and metamorphosis in the serpulid polychaete Hydroides elegans by dissolved free amino acids: isolation and identification
}

\author{
Tilman Harder*, Pei-Yuan Qian \\ Department of Biology, Hong Kong University of Science and Technology, Clearwater Bay, Kowloon, Hong Kong, ROC
}

\begin{abstract}
The calcareous tube-building polychaete Hydroides elegans (Haswell) is a major fouling organism in tropical waters around the world. In the marine environment, larvae of $H$. elegans rapidly settle and metamorphose in response to acceptable surface-bound bio-organic films. In addition to biological inducers, previous investigations by our group have indicated chemical inducers for larval settlement and metamorphosis in $H$. elegans. Crude samples derived from adult $H$. elegans and colonies of the bryozoan Bugula neritina induced a high percentage of larval metamorphosis in laboratory assays. Here, we describe a bioassay-guided isolation and purification of larval metamorphic inducers originating from these samples. Biologically active HPLC-purified fractions of both samples were composed of free amino acids. The entire free amino acid composition was determined by quantitation with ortho-phthaldialdehyde (OPA) and was found to be comprised of aspartic acid, glutamic acid, serine, histidine, glycine, arginine, alanine, asparagine, glutamine and taurine in concentrations ranging from $0.2 \mu \mathrm{M}$ (histidine) to $5.6 \mu \mathrm{M}$ (taurine). In the laboratory assay, the larval metamorphic response to an artificially prepared sample in identical concentrations of these amino acids was very similar to the natural isolates.
\end{abstract}

KEY WORDS: Hydroides elegans - Bugula neritina - Amino acid P Polychaete - Bio-organic film Metamorphic inducer - Larvae

\section{INTRODUCTION}

The life cycle of many benthic marine invertebrates includes a planktonic larval phase. Free swimming larvae must locate acceptable substrata to attach onto in order to begin their benthic life phase. The larvae of sessile marine invertebrates attach and metamorphose in response to a wide range of stimuli during the course of substratum selection (reviewed by Crisp 1974, Pawlik 1992, Rodriguez et al. 1993). Generally, the fact that a settlement cue is required may indicate that larval settlement patterns are not completely random. It has been suggested that in terms of a hierarchy of different stimuli, physical factors of the marine envi-

•E-mail: tharder@ust.hk ronment and physical properties associated with the substratum are subordinate to biological and chemical surface characteristics and signals (LeTourneux \& Bourget 1988, Pawlik 1992). Many marine invertebrate larvae are believed to respond to cues associated with the surface of conspecific individuals. Larval attachment on or close to conspecific adults has both advantages and disadvantages, such as maximization of reproductive success, protection against predators, and competition for space and food if the aggregation exceeds certain densities. Nevertheless, owing to the prevalence of gregariousness in hard-substratum marine communities, the benefits of this phenomenon seem to outweigh the costs (Pawlik 1992).

The calcareous tube-building polychaete Hydroides elegans (Haswell) is a major fouling organism in Hong Kong waters and is abundant in tropical and 
subtropical coastal fouling communities. Larval attachment and metamorphosis in $H$. elegans is induced by acceptable bio-organic films (Hadfield et al. 1994, Lau \& Qian 1997, Qiu \& Qian 1997, Walters et al. 1997) whereas larval settlement patterns are explained by passive larval deposition in crevices of roughness elements, followed by selective attachment to an acceptable bio-organic film (Walters et al. 1997). Early investigations in our laboratory into factors that induce larval attachment and metamorphosis other than natural biofilm and physical environmental determinants were the first attempts to explain gregarious larval settlement patterns of $H$. elegans via chemical inducers. In laboratory assays, Bryan et al. (1997) observed that a homogenate of conspecific juveniles and adults of $H$. elegans from Hong Kong waters induced 39 and $81 \%$ larval metamorphosis after periods of 48 and $96 \mathrm{~h}$, respectively. A homogenate of calcareous tubes alone was biologically inactive. Bryan et al. (1997) suggested that the assumed chemical inducer originated from the worm body itself. Moreover, Bryan et al. (1998) observed that $H$. elegans preferentially colonized the surfaces of the bryozoan Bugula neritina rather than a variety of other surfaces available in the field, such as subtidal rocks, a cement pier and nylon ropes. In laboratory experiments, larvae of $H$. elegans settled and metamorphosed on branches of $B$. neritina and on the bottom of dishes containing a naturally released exudate of $B$. neritina. The extraction of the leachate and subsequent bioassay analysis of the extract resulted in $74 \%$ larval metamorphosis after $96 \mathrm{~h}$ exposure. Bryan et al. (1998) suggested a chemically mediated relationship between larval settlement of $H$. elegans and compounds present in the leachate of $B$. neritina.

The objective of this study was to verify the existence of chemical larval inducers in sources that have been reported to contain bioactive metamorphic cues triggering larval attachment and metamorphosis in Hydroides elegans. We intended to gain a deeper understanding of potential chemical factors inducing larval settlement in $H$. elegans by isolation, elucidation and subsequent comparison of bioactive chemical components putatively present in the homogenate of $H$. elegans adults and in leachate of Bugula neritina. Owing to the distinct settlement behavior of larvae of $H$. elegans in laboratory assays, i.e the larval settlement rate is effectively enhanced in the presence of a settlement cue as compared to filtered seawater (FSW) controls (Bryan et al. 1997), we attempted a bioassay-guided isolation procedure. The bioassay procedure in this study was similar to the methodology previously applied by Bryan et al. (1997) and Bryan et al. (1998) and was specifically designed to correlate the larval metamorphic response with the efficacy of a chemical inducer.

\section{MATERIALS AND METHODS}

Larval culture and bioassay procedures. Adult Hydroides elegans were obtained from 2 sources. Worms were collected in the field from February to July, when monospecies aggregations were abundant on submerged rafts at a fish farm in Port Shelter Bay, Hong Kong $\left(22^{\circ} 19^{\prime} \mathrm{N}, 114^{\circ} 16^{\prime} \mathrm{W}\right)$. From August to January, when the reproductive activity of $H$. elegans decreased in the field due to low salinity caused by heavy rainfalls (Qiu \& Qian 1997), a laboratory broodstock was used. The adults were induced to spawn according to the method described in Bryan et al. (1997) and Qiu \& Qian (1997). Using this procedure, we obtained batches of larvae with mixed parentage and low variation in larval size for bioassays. In some batches, $4 \mathrm{~d}$ old larvae were reared in FSW $(0.22 \mu \mathrm{m})$ containing antibiotics $\left(2.5 \times 10^{-4} \mathrm{M}\right.$ streptomycin and $10 \times 10^{-5} \mathrm{M}$ penicillin) to the competent stage.

Bioassays under sterile conditions were performed following the detailed methodology described in Bryan et al. (1997) and Bryan et al. (1998). Metamorphic competence was determined by both examination of larval morphology (Wisely 1958) and a fast preliminary bioassay with the phosphodiesterase inhibitor 3-isobutyl-1-methylxanthine (IBMX) according to the methods described in Pechenik \& Qian (1998) and Qian \& Pechenik (1998). In addition to the methods cited, samples were generally filter sterilized $(0.22 \mu \mathrm{m})$ prior to their investigation in the bioassay. Unless otherwise stated, bioassays were performed without the addition of antibiotics. When metamorphic compounds were investigated in the presence of antibiotics $\left(2.5 \times 10^{-4} \mathrm{M}\right.$ streptomycin and $10 \times 10^{-5} \mathrm{M}$ penicillin), antibiotic-treated larvae were used in the bioassay.

Sample preparation I: homogenate of Hydroides elegans adults. Three hundred adult worms of mixed sexes were individually separated from their tubes with forceps under a dissecting microscope. Only individuals that were not damaged by this procedure were collected for sample preparation. The worms were transferred into a $50 \mathrm{ml}$ plastic vial containing $10 \mathrm{ml}$ of water (Millipore, Milli-Q Reagent-Water-System) and stored at $-20^{\circ} \mathrm{C}$. The defrosted sample was homogenized and centrifuged at $4000 \mathrm{rpm}(1935 \times \mathrm{g})$ for 10 min. The aqueous supernatant was decanted and the precipitate was subsequently extracted 3 times with $1 \mathrm{ml}$ water in consecutive steps. Supernatants were combined and freeze-dried, yielding $192 \mathrm{mg}$ of lyophilisate. The dried extract was stored at $-80^{\circ} \mathrm{C}$ until use. An aliquot of the extract was adjusted to the concentration of $0.1 \mathrm{mg}$ lyophilisate $\mathrm{ml}^{-1} \mathrm{FSW}$. In order to evaluate whether the metamorphic response was concentration dependent, a dilution series of $0.1,0.01$, 
0.001 and $0.0001 \mathrm{mg}$ lyophilisate $\mathrm{ml}^{-1} \mathrm{FSW}$ was bioassayed. The amino acid composition and concentration in the aqueous extract of homogenate of adults of $H$. elegans in the concentration of $0.1 \mathrm{mg}$ lyophilisate $\mathrm{ml}^{-1}$ FSW was determined by precolumn derivatization with ortho-phthaldialdehyde (OPA).

Sample preparation II: Hydroides elegans conditioned seawater. Laboratory: A cluster of a monospecies colony of $H$. elegans (1850 tubes with a gray deposit embedded in between, $28 \mathrm{~g}$ ) collected from a fish farm in Port Shelter Bay in April 1998 was placed in a glass beaker with $140 \mathrm{ml} \mathrm{FSW}$ for $1 \mathrm{~min}$. While we gently swirled the cluster, carefully avoiding any damage to tubes or injury to worms, the colony fell into smaller subcompartments and released parts of the deposit. After precipitation of suspended material, a $30 \mathrm{ml}$ aliquot was sampled, filter sterilized $(0.22 \mu \mathrm{m})$, subdivided into 5 replicates and immediately bioassayed. One $\mathrm{ml}$ of the sample was stored at $-80^{\circ} \mathrm{C}$. A control was prepared by performing the same procedure with FSW.

Field: At the same site, $25 \mathrm{ml}$ aliquots of seawater were sampled in sterilized syringes in direct proximity $(<0.5 \mathrm{~cm})$ to aggregations of Hydroides elegans adults in $0.5 \mathrm{~m}$ water depth (10 replicates). Seawater control samples were taken in a distance of $1 \mathrm{~m}$ to the aggregation in the same water depth. Samples were immediately filter sterilized $(0.22 \mu \mathrm{m})$, frozen in liquid nitrogen and subsequently stored at $-80^{\circ} \mathrm{C}$. The amino acid composition and concentration in $H$. elegans conditioned FSW and the control samples was determined by precolumn derivatization with OPA.

Sample preparation III: Hydroides elegans gamete conditioned seawater. Tubes containing sexually mature individuals were carefully cleaned in FSW and gently cracked with forceps under a dissecting microscope. One individual (whilst in the broken tube) was placed in a cell well (Corning 25820) containing $1 \mathrm{ml}$ FSW. When we touched the operculum slightly, gametes were generally released from individuals in a viscous string through the posterior end. After specimens had been removed, potentially water-soluble compounds in the germ cells' covering fluid were dissolved by stirring. Suspended gametes were centrifuged $(4500 \mathrm{rpm}[2449 \times \mathrm{g}], 3 \mathrm{~min})$ and the clear supernatants were filter sterilized and stored at $-80^{\circ} \mathrm{C}$. The amino acid composition and concentration in the germ cells' covering fluid of 10 males and 10 females in $10 \mathrm{ml}$ FSW each was determined by precolumn derivatization with OPA.

Sample preparation IV: Bugula neritina conditioned seawater. Colonies of $B$. neritina $(500 \mathrm{ml}$ volume displacement in a graduated cylinder filled with FSW) were freshly collected in February 1997 at the same site as Hydroides elegans. They were placed in
$4 \mathrm{l}$ beakers containing $3 \mathrm{l} \mathrm{FSW}$ for a period of $60 \mathrm{~min}$ at $23^{\circ} \mathrm{C}$, enriching the water with a bright purple leachate (Bryan et al. 1998). The leachate was filtered $(0.22 \mu \mathrm{m})$ and stored at $-80^{\circ} \mathrm{C}$ until use. An aliquot of this sample was $1 / 10$ diluted with FSW and immediately bioassayed along with $H$. elegans gamete conditioned FSW. The amino acid composition and concentration in $1 / 10$ diluted $B$. neritina conditioned FSW was determined by precolumn derivatization with OPA.

Adjustment of sample concentrations during bioassay-guided isolation. Different isolation procedures were performed in order to evaluate their application for (1) concentration of the bioactive component, and (2) separation of biologically inactive sample components. After an isolation procedure with a bioactive sample had been performed, the distribution of sample components in the resulting isolates was unknown. The resulting isolates were concentrated and redissolved in the same volume of FSW as the preceding sample in order to adjust the concentration of bioactive compounds to be equivalent to that in the original sample. By investigating these isolates in the bioassay, it was possible to evaluate whether bioactive compounds were (1) enriched in a single isolate (very similar metamorphic response to the treatment with the preceding sample), or (2) distributed in more than 1 isolate (lower metamorphic response than the treatment with the preceding sample).

Bioassays with the aqueous extract of adult Hydroides elegans homogenate (see 'Sample preparation I') indicated a maximum metamorphic response at a concentration of $0.1 \mathrm{mg}$ lyophilisate $\mathrm{ml}^{-1} \mathrm{FSW}$. Therefore, isolates were adjusted to the same concentration of bioactive compounds as in the aqueous extract in order to compare the metamorphic responses of isolates obtained from different purification procedures.

Isolation and purification procedure I: solid-liquid extraction (SLE). To determine whether the metamorphic inducer was selectively extractable from the lyophilisate of the aqueous extract of adult Hydroides elegans homogenate, an aliquot of $5 \mathrm{mg}$ lyophilisate was extracted 3 times with $3 \mathrm{ml}$ methanol for $30 \mathrm{~min}$ at $8^{\circ} \mathrm{C}$ in consecutive steps periodically agitating and sonicating the mixture. The solvent extracts were combined and dried in nitrogen (methanol extract, ME). The methanol extraction residue (MER) was dried under vacuum. Both the ME and the MER were completely redissolved in $50 \mathrm{ml} \mathrm{FSW}$ and bioassayed. As a blank control, $9 \mathrm{ml}$ methanol was dried in a rotor evaporator and the potential residue was redissolved in $50 \mathrm{ml} \mathrm{FSW} \mathrm{(MeOH} \mathrm{blank).}$

Isolation and purification procedure II: solid-phase extraction (SPE). Alternatively, SPE was performed to divide the aqueous extract into fractions of different 
polarity. One $\mathrm{ml}$ of the aqueous extract $(32 \mathrm{mg}$ lyophilisate $\mathrm{ml}^{-1}$ water) was applied to a preconditioned reversed phase octadecylsilane extraction column (J. T. Baker, $3 \mathrm{ml}$ volume, $500 \mathrm{mg}$ sorbent weight). Processing the column by vacuum, it was firstly eluted with $3 \mathrm{ml}$ water (polar fraction) and subsequently with $3 \mathrm{ml}$ methanol (nonpolar fraction). Fractions were dried in vacuum, redissolved in $1 \mathrm{ml}$ water and subsequently bioassayed.

Isolation and purification procedure III: ultrafiltration. To estimate the molecular weight of bioactive compounds, an aliquot of the aqueous extract of adult Hydroides elegans homogenate at a concentration of $0.1 \mathrm{mg}$ lyophilisate $\mathrm{ml}^{-1}$ water was ultrafiltered (Amicon Ultrafiltration cell, $350 \mathrm{ml} ; 500$ Dalton Diaflo membrane YC05). The ultrafiltrate $(<0.5 \mathrm{kDa})$ and the filter residue $(>0.5 \mathrm{kDa})$ were freeze-dried, redissolved in the same volume of FSW as the unfiltered aliquot and subsequently bioassayed

Isolation and purification procedure IV: liquid chromatography. High-performance liquid chromatography (HPLC), gel-filtration chromatography (GFC) and thin-layer chromatography (TLC) were applied to isolate bioactive samples originating from Hydroides elegans and Bugula neritina.

One $\mathrm{ml}$ of the aqueous extract of adult Hydroides elegans homogenate (32 $\mathrm{mg}$ lyophilisate $\mathrm{ml}^{-1}$ water) was solid-phase extracted. The resulting polar fraction was ultrafiltered prior to HPLC and GFC in order to prevent retention of high molecular weight compounds at the column entrance and to improve chromatographic resolution by reducing the complexity of the sample composition. The $0.5 \mathrm{kDa}$ ultrafiltrate of the aqueous extract of adult $H$. elegans homogenate was concentrated, redissolved in $1 \mathrm{ml}$ water and further separated in a series of 5 chromatographic steps by HPLC and GFC.

HPLC was carried out with a Waters HPLC system connected to a photodiode array detector (Waters 996). Depending on the sample volume, reversed-phase columns of analytical (Merck, LiChrospher-100, RP 18 endcapped, $250 \times 4 \mathrm{~mm}$, particle size $5 \mu \mathrm{m}$ ) and semipreparative scale (CS, Nucleosil-100, RP 18 endcapped, $250 \times 10 \mathrm{~mm}$, particle size $10 \mu \mathrm{m}$ ) were provided. The following mobile phases were either applied isocratically or as binary linear gradients: Milli-Q water ( $\mathrm{pH}$ 5.5), water/0.1\% trifluoroacetic acid (TFA) (pH 2.1) and water/methanol (40/60 v/v). All solvents and solvent mixtures were degassed for at least $30 \mathrm{~min}$ prior to usage and during chromatography (Helium, $10 \mathrm{ml} \mathrm{min}^{-1}$ ). Chromatographic parameters are given in the figure legends.

GFC was performed with polyacrylamide gel (BIORAD, Bio-Gel-P2, fractionation range: 100 to $1800 \mathrm{Da}$ ) packed in a Pharmacia $C-16$ column $(60 \times 1.6 \mathrm{~cm})$. The column was attached to the HPLC system described above. Helium saturated Milli-Q water was used as the mobile phase. Chromatographic parameters are given in the figure legends.

HPLC and GFC samples were fractionated according to the elution profile in the real time plot of the chromatogram. Fractionation criteria were peak minima between resolved peaks and the change in detection of distinct UV spectra within unresolved peaks (see Figs. $4 \mathrm{~A}$ to $8 \mathrm{~A}$, fractionation steps indicated by vertical dotted lines). Sampled fractions were dried by rotor evaporation or freeze-drying, redissolved in FSW and bioassayed. The selection of mobile phases and additional buffers was limited to the eluents mentioned above because they could be completely removed without leaving any residues of buffer salts. The metamorphic compounds were purified and isolated by repeated chromatography of bioactive fractions and variation of chromatographic elution parameters (bioassay-guided fractionation)

TLC was performed on precoated layers of silica gel60 (Merck, $20 \times 20 \mathrm{~cm}, 0.2 \mathrm{~mm}$ ) for qualitative sample analysis with specific postchromatographic staining reactions. Aqueous sample solutions were spotted onto the layer with a microliter syringe. Three mobile phase systems were used for chromatographic development: n-propanol/water (70/30 v/v), 1-butanol/99.8\% acetic acid/water $(80 / 20 / 20 \mathrm{v} / \mathrm{v} / \mathrm{v})$, n-propanol $/ 25 \%$ ammonium hydroxide (70/30 v/v) (Stahl 1969). TLC was carried out in a separation chamber for ascending development. Spots were visualized with the following reagents: iodine vapor (general reagent for unsaturated carbon bonds), ninhydrin-collidine reagent (for primary amines, amino acids, oligopeptides), chlorine/ o-tolidine (for nitrogen-containing compounds that are convertible to chloramines), sulfuric acid (general reagent for oxidizable compounds), and anisaldehydesulphuric acid (for sugars, steroids, terpenes) (Stahl 1969, Jork et al. 1990). Additionally, samples were developed on separate layers and stained in the sequence: (1) ninhydrine-collidine and (2) chlorine /o-tolidine. After derivatization, visible spots were immediately marked for the calculation of retention factors (Rf), presented as hRf $=\mathrm{Rf} \times 100$. Characteristics like spot shape, resolution, and color were noted for the comparison with standards

Free amino acid analysis. Qualitative and quantitative analysis of dissolved free amino acids (DFAA) was performed by precolumn derivatization with OPA using reversed-phase HPLC (Lindroth \& Mopper 1979). The HPLC system described above was equipped with a fluorescence detector (Waters 474, excitation wavelength $330 \mathrm{~nm}$, emission wavelength $418 \mathrm{~nm}$ ) and a LiChrospher-100, RP-18e column $(250 \times 4 \mathrm{~mm}$, particle size $5 \mu \mathrm{m}$, Merck). Gradient elution at $1.1 \mathrm{ml} \mathrm{min}^{-1}$ was 
performed as follows: Solvent $A$, tetrahydrofuran/ methanol/0.05 $\mathrm{M}$ sodium acetate $(1 / 19 / 80 \mathrm{v} / \mathrm{v} / \mathrm{v})$; solvent $B$, methanol $/ 0.05 \mathrm{M}$ sodium acetate $(8 / 2 \mathrm{v} / \mathrm{v})$; elution profile: 0 to $15 \% \mathrm{~B}$ within $1 \mathrm{~min}, 15 \% \mathrm{~B}$ for $8 \mathrm{~min}$, 15 to $30 \% \mathrm{~B}$ within $1 \mathrm{~min}, 30 \% \mathrm{~B}$ for $4 \mathrm{~min}, 30$ to $50 \%$ $\mathrm{B}$ within $4 \mathrm{~min}, 50 \% \mathrm{~B}$ for $2 \mathrm{~min}, 50$ to $100 \% \mathrm{~B}$ within $12 \mathrm{~min}, 100$ to $0 \% \mathrm{~B}$ within $3 \mathrm{~min}$, and $15 \mathrm{~min}$ re-equilibration. Amino acids and standard solutions in concentrations of $50,10,1,0.1 \mathrm{mmol}^{-1}$ were obtained from Sigma Chemical Co. or prepared in water. DFAA were identified by spiking with standards. Quantitation was performed with the external standard method. Calibration curves based on peak area were generated over 2 points corresponding to standards covering the DFAA concentration range of the sample under investigation (Millenium software, v2.15).

All solvents and chemicals used in this study were reagent grade and water was Milli-Q quality. Unless otherwise stated, seawater was $0.22 \mu \mathrm{m}$ filtered.

Isolation and purification procedure V: Bugula neritina. A bioassay-guided separation procedure like the one described in this study for the adult Hydroides elegans homogenate was applied to $B$. neritina leachate. Flash chromatography with XAD-2 (glass column, $30 \times$ $3 \mathrm{~cm}$ ) was performed according to the methods described in Bryan et al. (1998).

Statistical analysis. The data on percentage of larval metamorphosis in response to experimental treatments were arcsine-transformed before statistical analysis was carried out. Replicates in which no larvae metamorphosed were given the value of $1 / 4 n$ ( $n=$ number of larvae in a single treatment) to improve the arcsine transformation (Zar 1996). The normality assumption was verified with Shapiro-Wilk's $W$-test (Shapiro \& Wilk 1965). To analyze the data, 1-way ANOVA followed by Tukey's multiple comparisons test $(\alpha=0.05)$ was performed. Data that did not meet the normality assumption of parametric analysis were analyzed using nonparametric statistics. This was done by trans- forming values to ranks and then applying 1-way ANOVA followed by Tukey's multiple comparisons test $(\alpha=0.05)$ to the data (Conover \& Iman 1981). In the final experiment, data were analyzed by 2 -way ANOVA with equal replicates to compare larval metamorphic responses to biologically active samples in assays with and without presence of antibiotics. Percentage data in these 2 different treatments were arcsine-transformed and compared with Mann-Whitney $U$-test (Zar 1996). The figure legends state which statistical analysis was used in individual cases. The data presented in all figures are not transformed.

\section{RESULTS}

\section{Larval metamorphosis in response to samples originating from Hydroides elegans and Bugula neritina}

After $48 \mathrm{~h}$, the aqueous extract of adult Hydroides elegans homogenate in the relative concentration of $0.1 \mathrm{mg}$ lyophilisate $\mathrm{ml}^{-1}$ FSW induced $64 \%$ larval metamorphosis (Fig. 1A). This response was significantly higher than in dilution treatments with 0.01 , 0.001 and $0.0001 \mathrm{mg}$ lyophilisate $\mathrm{ml}^{-1}$ FSW and the FSW control ( $p<0.05$, Tukey's test). No significant difference in percentage of larval metamorphosis was observed among the treatments of $0.01,0.001$, and $0.0001 \mathrm{mg}$ lyophilisate $\mathrm{ml}^{-1}$ FSW and the FSW control ( $p>0.07$, Tukey's test). The FSW samples conditioned with $H$. elegans and Bugula neritina colonies in the laboratory induced a significantly higher percentage of larval metamorphosis after $48 \mathrm{~h}$ than the FSW control (Fig. 1B, p $<0.005$, Tukey's test). No significant difference in percentage of larval metamorphosis was observed between the seawater sample gained in close proximity to a $H$. elegans colony in the field and the FSW control (Fig. 1B, $\mathrm{p}=0.97$ ).
Fig. 1. Percentage of larval metamorphosis after $48 \mathrm{~h}$ in response to samples originating from Hydroides elegans and Bugula neritina. (A) Mean percentage in response to 4 different concentrations of the aqueous extract of adult $H$. elegans homogenate. Data plotted are means + SD of 6 replicates. (B) Mean percentage in response to FSW (filtered seawater, $0.22 \mu \mathrm{m}$ ) conditioned with $H$. elegans and $B$. neritina colonies in the laboratory (lab.) and a seawater sample taken in close proximity to a $H$. elegans colony in the field (field). Data plotted are means $+\mathrm{SD}$ of 5 replicates. Data that are significantly different are indicated by different letters above the bars (1-way ANOVA, p $<0.0001$ )
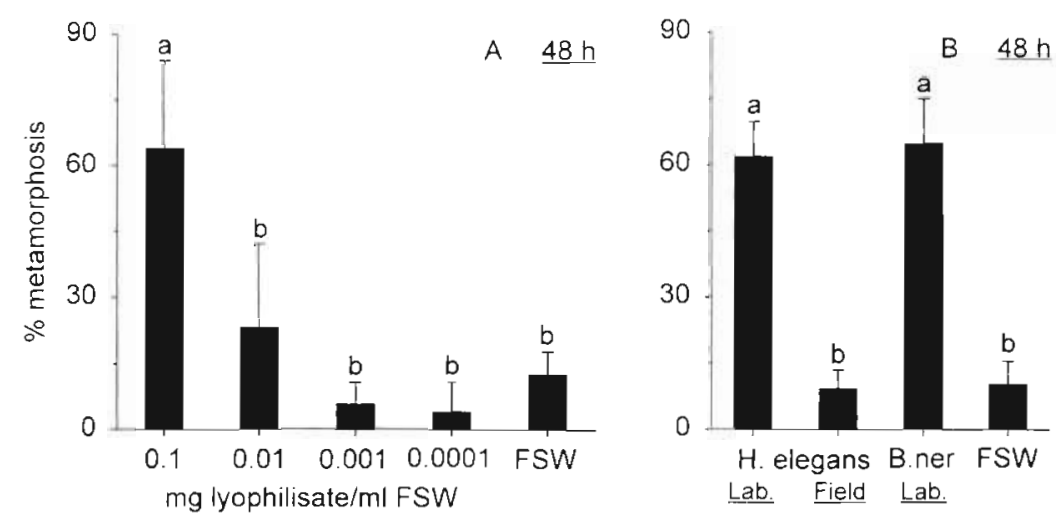

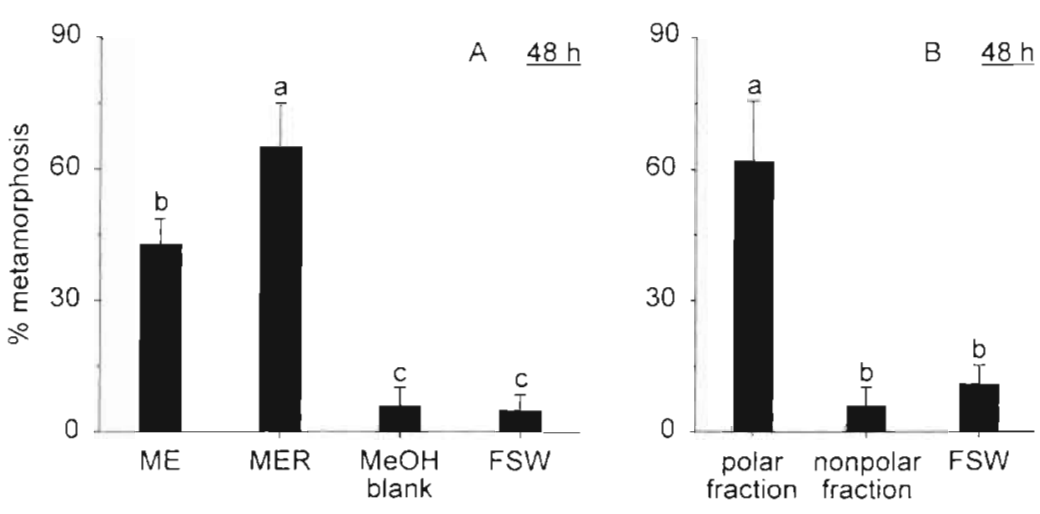

Fig. 2. Percentage of larval metamorphosis after $48 \mathrm{~h}$ in response to solid-liquid and solidphase fractions of aqueous extract of adult Hydroides elegans homogenate. (A) Mean percentage in response to the methanol extract (ME) and the methanol extraction residue (MER) of freeze-dried aqueous extract of adult $H$. elegans homogenate. A concentrated sample of the extraction solvent served as a blank control (MeOH blank). (B) Mean percentage in response to the polar (water) and the nonpolar (methanol) fraction from solid-phase extraction of the aqueous extract of adult $H$. elegans homogenate. Data plotted are means + SD of 5 replicates. Data that are significantly different are indicated by different letters above the bars ( 1 -way ANOVA, $p<0.0001$ )

\section{Larval metamorphosis in response to solid-liquid and solid-phase extracts of the aqueous extract of adult Hydroides elegans homogenate}

Both the MER and the ME induced significantly higher percentages of larval metamorphosis than the $\mathrm{MeOH}$ blank and the FSW control after $48 \mathrm{~h}$ (Fig. 2A, $\mathrm{p}<0.001$, Tukey's test). The MER induced $65 \%$ of larval metamorphosis, which was significantly higher than the $43 \%$ induced by the ME ( $p<0.05$, Tukey's test). No significant difference in percentage of larval metamorphosis was observed between treatments of the $\mathrm{MeOH}$ blank and the FSW control $(\mathrm{p}=0.98$, Tukey's test), indicating that potential impurities in the extraction solvent did not affect the bioassay result. The polar fraction induced $62 \%$ of larval metamorphosis after $48 \mathrm{~h}$, which was significantly higher than the percentages of larval metamorphosis induced by the nonpolar fraction and the FSW control (Fig, 2B, p < 0.001, Tukey's test). Larval metamorphosis induced by the nonpolar fraction was statistically the same as in the FSW control ( $p=0.37$. Tukey's test). These results indicate that SPE in contrast to SLE was a suitable method to isolate biologically inactive, nonpolar sample components.

\section{Larval metamorphosis in response to the ultrafiltrate and filter residue of an aqueous extract of adult Hydroides elegans homogenate}

The ultrafiltrate $(<0.5 \mathrm{kDa})$ induced $39 \%$ of larval metamorphosis after $48 \mathrm{~h}$, which was significantly higher than the percentages of larval metamorphosis induced by the filter residue (>0.5 kDa) and the FSW control (Fig. 3, p < 0.05, Tukey's test). The percentage of larval metamorphosis in the treatment with the filter residue was statistically the same as in the FSW control $(\mathrm{p}=1.0$, Tukey's test). These results indicate that ultra-

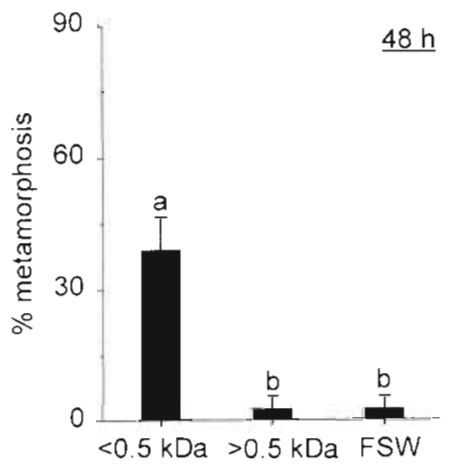

Fig. 3. Mean percentage of larval metamorphosis after $48 \mathrm{~h}$ in response to the ultrafiltrate $(<0.5 \mathrm{kDa})$ and the filter residue $(>0.5 \mathrm{kDa}$ ) of the aqueous extract of adult Hydroides elegans homogenate. Data plotted are means + SD of 4 replicates. Data that are significantly different are indicated by different letters above the bars (1-way ANOVA, $\mathrm{p}<0.05$ )

filtration was a suitable method to isolate biologically inactive sample components with a molecular weight higher than 500 Da.

Bioassay-guided chromatography - larval metamorphosis in response to HPLC and GFC fractions

\section{Hydroides elegans}

In the first chromatographic step by HPLC, bioactive compounds in the aqueous extract of adult Hydroides elegans homogenate were separated (Fig. 4A). Fraction F-1A (1.5 to 7.0 min) correlated with isochratic aqueous elution; Fraction F-2A (7.0 to $17.0 \mathrm{~min}$ ) correlated with isochratic elution of methanol/water $(60 / 40 \mathrm{v} / \mathrm{v})$. Both fractions were bioassayed (Fig. 4B). After 48 h, Fraction F-1A induced a significantly higher percentage of larval metamorphosis $(40 \%)$ than Fraction F-2A and the FSW control ( $p<0.001$, Tukey's test). The percentage of larval metamorphosis in the treatment with Fraction F-2A was statistically the same as in the FSW control ( $p=0.89$, Tukey's test $)$, indicating that metamorphic compounds were exclusively present in Fraction F- 

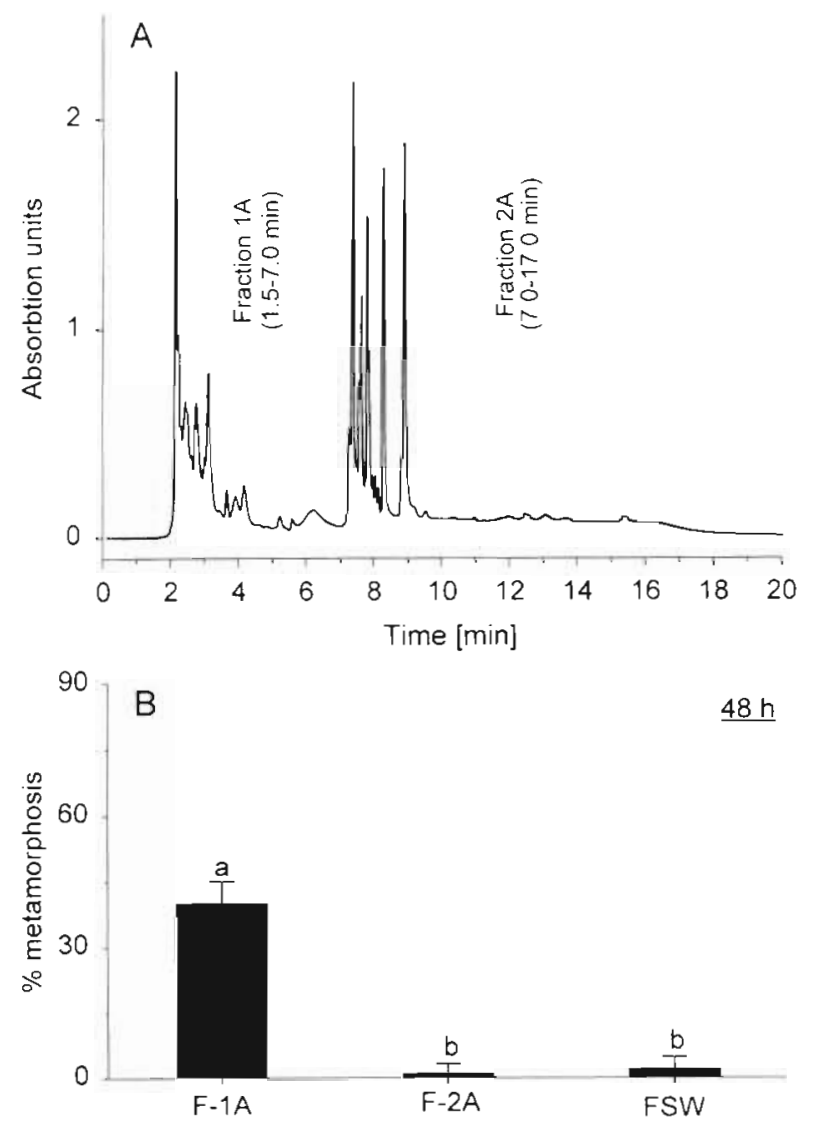

Fig. 4. (A) First chromatographic step (HPLC). Sample volume: $75 \mu l_{i}$ column: LiChrospher-100, RP 18 endcapped, 250 $\times 4 \mathrm{~mm}$, particle size $5 \mu \mathrm{m}$; detection: PDA 200-400 nm; mobile phase: A water, B methanol/water $(60 / 40 \mathrm{v} / \mathrm{v}), 0-6$ $\min 100 \% \mathrm{~A}, 6-16 \min 90 \% \mathrm{~B}, 16-20 \min 100 \% \mathrm{~A}$; flow: $1 \mathrm{ml}$ $\mathrm{min}^{-1}$ Fractionation profile is indicated by vertical dotted lines. (B) Mean percentage of larval metamorphosis after $48 \mathrm{~h}$ in response to Fractions F-1A and F-2A of the first chromatographic step. Data plotted are means + SD of 5 replicates. Data that are significantly different are indicated by different letters above the bars (1-way ANOVA, $p<0.001$ )

1A. In the second chromatographic step, Fraction F$1 \mathrm{~A}$ was rechromatographed and the 3 resulting subfractions, F-1B to F-3B, were bioassayed (Fig. $5 \mathrm{~A}, \mathrm{~B}$ ). After $48 \mathrm{~h}$, Fraction F-2B (2.8 to $3.2 \mathrm{~min}$ ) induced significantly higher percentage of larval metamorphosis (55\%) than Fractions F-1B (1.2 to $2.8 \mathrm{~min})$ and F-3B (3.2 to $7.0 \mathrm{~min}$ ) and the FSW control $(\mathrm{p}<0.05$. Tukey's test). The percentage of larval metamorphosis in treatments of Fractions F-1B and F-3B was statistically the same as in the FSW control ( $p>0.17$, Tukey's test), indicating that metamorphic compounds were mainly present in Fraction F-2B. In the third chromatographic step, Fraction F-2B was rechromatographed with mobile phases of different $\mathrm{pH}$-values; water $(\mathrm{pH} 5.5)$ and water $/ 0.1 \%$ TFA. (pH 2.1) (Fig. 6A). Fraction F-2B was separated at $\mathrm{pH}$
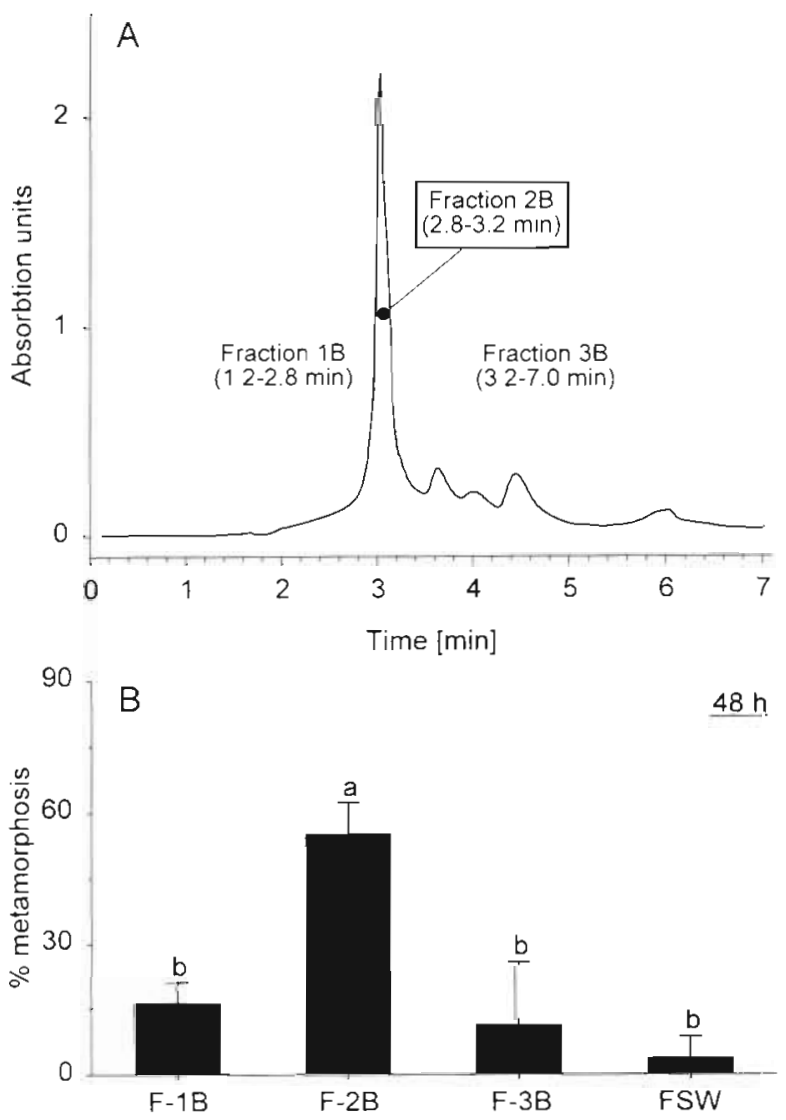

Fig. 5. (A) Second chromatographic step (HPLC). Sample volume: $500 \mu \mathrm{l}$; column: Nucleosil-100, RP 18 endcapped, $250 \times$ $10 \mathrm{~mm}$, particle size $10 \mu \mathrm{m}$; detection: PDA $200-400 \mathrm{~nm}$; mobile phase: A water, $B$ methanol/water $(60 / 40 \mathrm{v} / \mathrm{v}), 0-6$ $\min 100 \%$ A, $6-16 \min 90 \% \mathrm{~B}, 16-20 \min 100 \% \mathrm{~A}_{\text {; flow: } 6 \mathrm{ml}}$ $\mathrm{min}^{-1}$ Fractionation profile is indicated by vertical dotted lines. The part of the chromatogram from 7 to $20 \mathrm{~min}$ is not displayed. (B) Mean percentage of larval metamorphosis after $48 \mathrm{~h}$ in response to Fractions F-1B to F-3B. Data plotted are means + SD of 4 replicates. Data that are significantly different are indicated by different letters above the bars (1-way ANOVA, $\mathrm{p}<0.001\}$

2.1 into 3 sub-fractions for subsequent bioassays (Fig. 6B). After 48 h, Fraction F-2B.1 (2.5 to $3.2 \mathrm{~min}$ ) induced a significantly higher percentage of larval metamorphosis (46\%) than Fractions F-2B.2 (3.2 to $6.0 \mathrm{~min}$ ) and F-2B.3 (6.0 to $9.5 \mathrm{~min}$ ) and the FSW control $(\mathrm{p}<0.05$, Tukey's test). The percentage of larval metamorphosis in treatments of Fractions $F$ 2B.2 and F-2B.3 was statistically the same as in the FSW control $(\mathrm{p}>0.1$, Tukey's test $)$, indicating that metamorphic compounds were exclusively present in Fraction F-2B.1. In the fourth chromatographic step by GFC, Fraction F-2B.1 was rechromatographed and separated into 5 sub-fractions for subsequent bioassays (Fig. 7A,B). After 48 h, Fraction F-2B.1.4 (245 to $280 \mathrm{~min}$ ) induced a significantly higher percentage of larval metamorphosis than Fractions F-2B.1.1 (80 to 

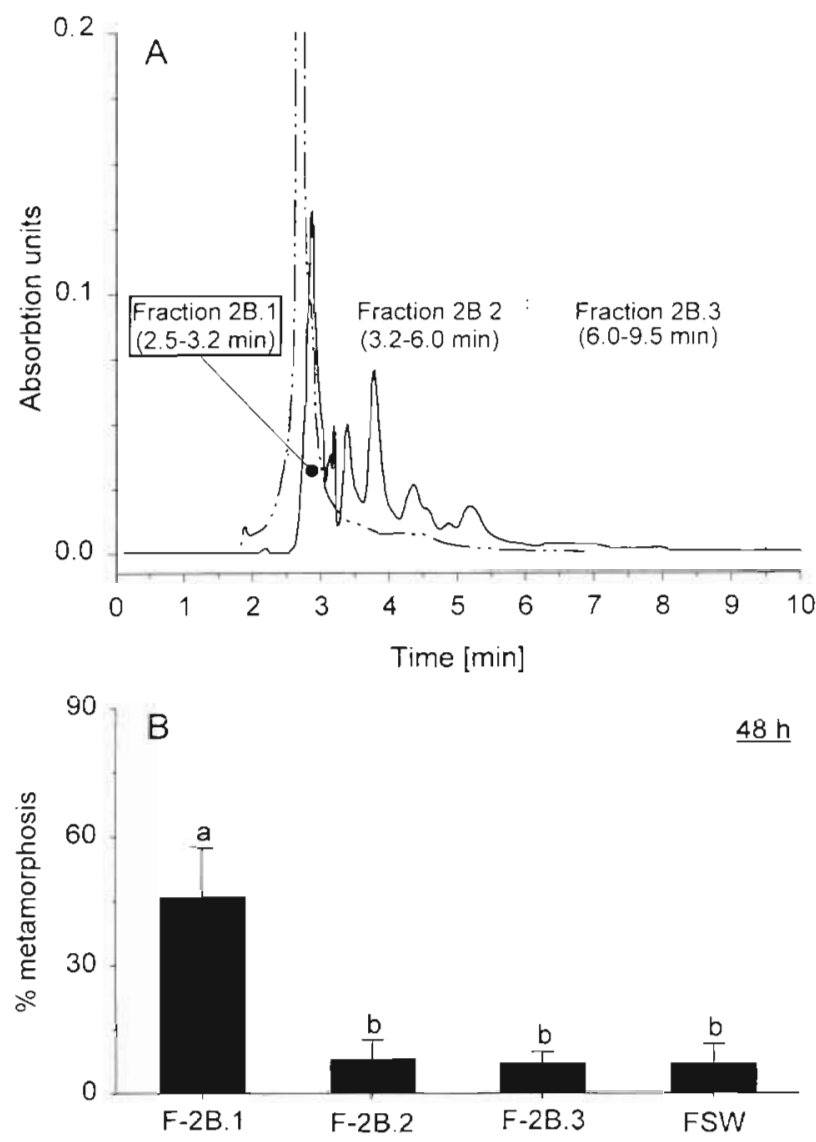

Fig. 6. (A) Third chromatographic step (HPLC). Sample volume: $50 \mu \mathrm{l}$; column: LiChrospher-100, RP 18 endcapped, 250 $\times 4 \mathrm{~mm}$, particle size $5 \mu \mathrm{m}$; detection: PDA $200-400 \mathrm{~nm}$; mobile phase: $\mathrm{A}$ water, $\mathrm{B}$ water $/ 0.1 \%$ TFA $; 0-10 \mathrm{~min} 100 \% \mathrm{~A}$ (dash-dotted line) and $0-10 \mathrm{~min} 100 \% \mathrm{~B}$ (solid line); flow: $1 \mathrm{ml} \mathrm{min}{ }^{-1}$. Fractionation profile is indicated by vertical dotted lines. (B) Mean percentage of larval metamorphosis after $48 \mathrm{~h}$ in response to Fractions F-2B. 1 to F-2B.3 of the third chromatographic step. Data plotted are means $+\mathrm{SD}$ of 5 replicates. Data that are significantly different are indicated by different letters above the bars ( 1 -way ANOVA, $p<0.05$ )

$180 \mathrm{~min}$ ), F-2B.1.2 (180 to $215 \mathrm{~min})$ and F-2B.1.5 (280 to $350 \mathrm{~min}$ ) and the FSW control ( $\mathrm{p}<0.05$, Tukey's test). No significant difference in larval metamorphosis was observed between treatments with Fractions F-2B.1.3 (215 to $245 \mathrm{~min}$ ) and F-2B.1.4 (245 to 280 min) $(p=0.65$, Tukey's test $)$. Therefore, metamorphic compounds were present in both Fractions F-2B.1.3 and F-2B.1.4. A comparison of mean percentage of larval metamorphosis of Fractions F-2B.1.3 (31\%) and F-2B.1.4 $(56 \%)$ with the elution profile between 215 and 280 min (overlapping signals, Fig. 7B) indicated that metamorphic compounds were predominantly present in Fraction F-2B.1.4. In the fifth chromatographic step by HPLC, the combined Fractions F-2B.1.3 and F-2B.1.4 were rechromatographed and
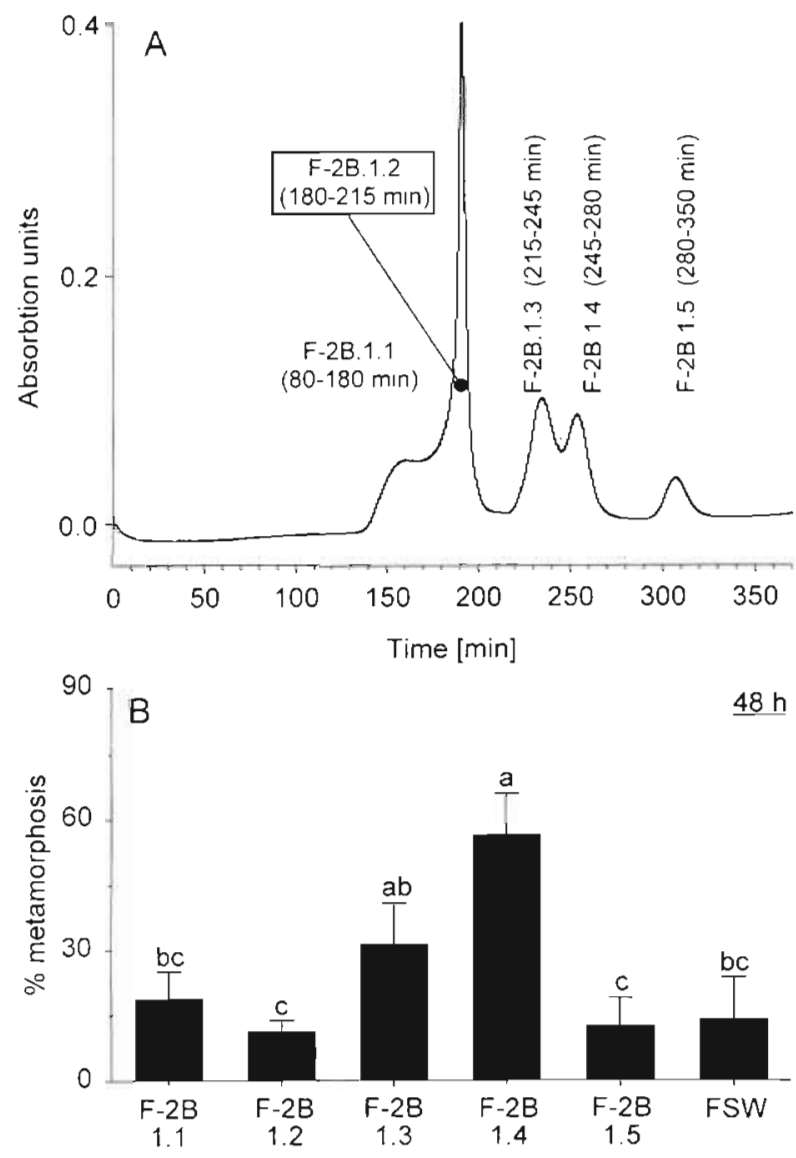

Fig. 7. (A) Fourth chromatographic step (GFC). Sample vol-

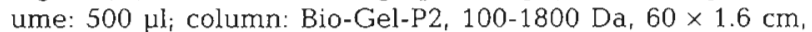
particle size 45-90 $\mu \mathrm{m}$; detection: PDA $200-400 \mathrm{~nm}$; mobile phase: water; flow: $0.2 \mathrm{ml} \mathrm{min}^{-1}$ Fractionation profile is indicated by vertical dotted lines. (B) Mean percentage of larval metamorphosis after $48 \mathrm{~h}$ in response to Fractions F-2B.1.1 to F-2B.1.5 of the fourth chromatographic step. Data plotted are means + SD of 4 replicates. Data that are significantly different are indicated by different letters above the bars (1-way ANOVA, $\mathrm{p}<0.001$ )

separated into 3 sub-fractions for subsequent bioassays (Fig. 8A,B). After $48 \mathrm{~h}$, the larval metamorphic response to Fractions F-2B.1.4.1 (2.4 to $4.2 \mathrm{~min}$ ) and F-2B.1.4.2 (4.2 to $5.6 \mathrm{~min}$ ) was significantly higher than to Fraction F-2B.1.4.3 (5.6 to $8.0 \mathrm{~min}$ ) and the FSW control $(p<0.05$, Tukey's test). Percentage of larval metamorphosis in the treatment with Fraction F-2B.1.4.3 was statistically the same as in the FSW control ( $p=0.97$, Tukey's test), demonstrating that metamorphic compounds were distributed in Fractions F-2B.1.4.1 and F-2B.1.4.2. In a repetition of this experiment, the signal between 2.4 and 5.6 min was sampled in a single fraction, F-2B.1.4.(1+2), and subsequently bioassayed. After $48 \mathrm{~h}$, this fraction induced $52 \%$ of larval metamorphosis, which was not 

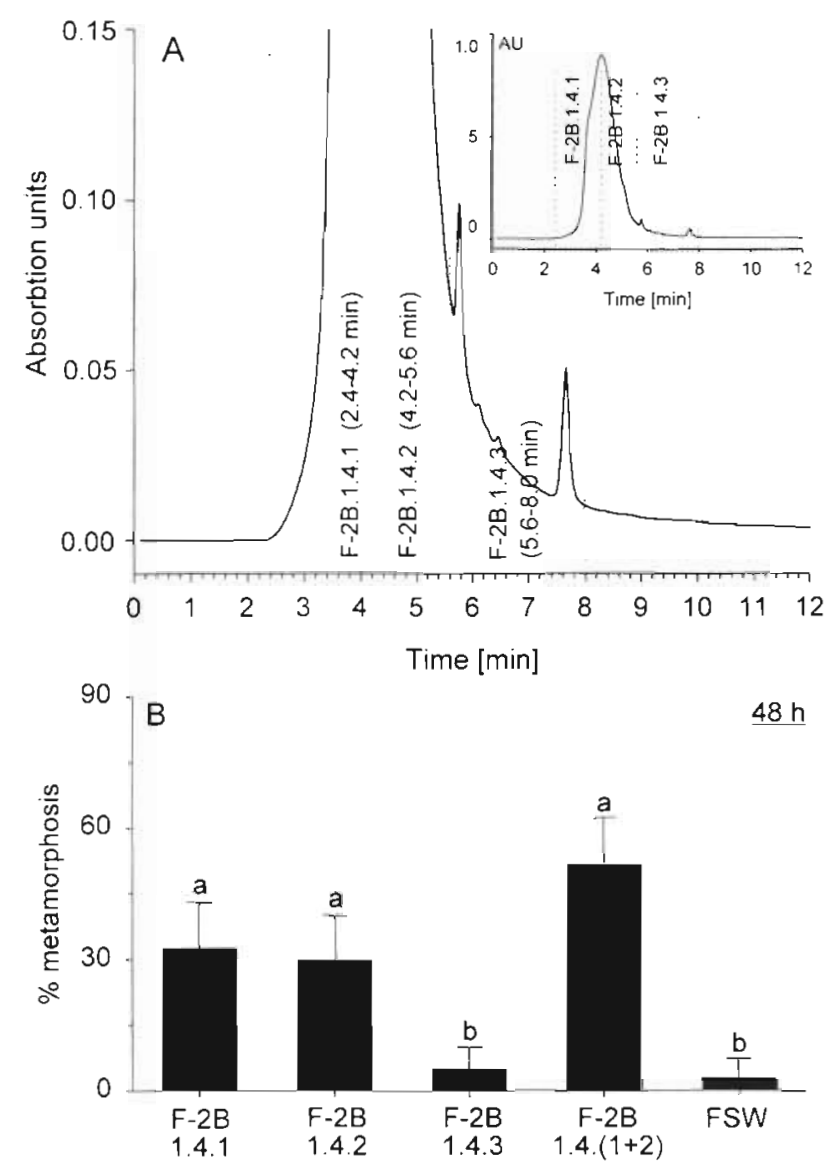

Fig. 8. (A) Fifth chromatographic step (HPLC). Sample vol-

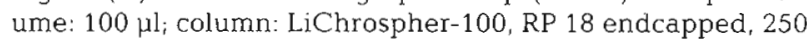
$\times 4 \mathrm{~mm}$, particle size $5 \mu \mathrm{m}$; detection: PDA 200-400 $\mathrm{nm}$;

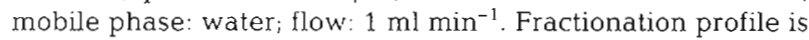
indicated by vertical dotted lines. This figure represents a magnification ( 0.0 to 0.15 absorption units, $A U)$ of the cornplete chromatogram displayed in the upper right corner. (B) Mean percentage of larval metamorphosis after $48 \mathrm{~h}$ in response to Fractions F-2B1.4.1 to F-2B1.4.3 and F2B1.4.(1+2). Data plotted are means + SD of 5 replicates. Data that are significantly different are indicated by different letters above the bars (1-way ANOVA, $p<0.001)$ significantly different from Fractions F-2B.1.4.1 and F-2B.1.4.2 ( $\mathrm{p}>0.27$. Tukey's test).

\section{Bugula neritina}

The application of a bioassay-guided separation procedure like the one described in this study for adult Hydroides elegans homogenate to Bugula neritina leachate revealed a bioactive fraction with comparable chemical and biological characteristics. The biological activity was restricted to a HPLC fraction with chromatographic retention values similar to Fraction F-2B.1 (Fig. 6A). The amino acid composition and concentration in this HPLC fraction was determined by precolumn derivatization with OPA. Detailed chromatographic data are not published in this study.

\section{Qualitative analysis of separated TLC spots}

The bioactive HPLC Fractions F-2B.1.4.1 and F2B.1.4.2 were further separated by TLC. The mobile phase n-propanol/25\% ammonium hydroxide was found to reveal optimal chromatographic resolution Separate visualization with the reagents ninhydrincollidine and chlorine/o-tolidine indicated compounds with primary amino functions and/or intramolecular amide-bonds. The other staining methods were negative. Consecutive application of ninhydrin-collidine and chlorine/o-tolidine revealed no spots. This result suggested that the isolate did not contain compounds with intramolecular amide bonds. Fractions F-2B.1.4.1 and F-2B.1.4.2 revealed identical chromatographic results (Table 1). Fraction F-2B.1.4.3 was not stained with any of the reagents. By detailed comparison of the retention data and characteristic staining reactions with those of free amino acids (L-isomers), we identi-

Table 1. Results of the separation of Fractions F-2B.1.4.1 to F-2B.1.4.3 by thin-layer chromatography. Values are presented as retention factors ( $h \mathrm{Rf}$ ) and spot colors revealed by different visualization reagents (see 'Materials and methods'); reference staining reactions of free amino acids (L-Asp: aspartic acid; L-Glu: glutamic acid; Gly: glycine; Tau: taurine) are given for comparison

\begin{tabular}{|c|c|c|c|c|}
\hline $\begin{array}{l}\text { Fraction/ } \\
\text { reference }\end{array}$ & hRf Spot 1 & \multicolumn{2}{|c|}{ TLC solvent: n-propanol $/ 25 \%$ ammonium hydroxide $(70 / 30 \mathrm{v} / \mathrm{v})$} & (v) hRf Spot 4 \\
\hline$F-2 B .1 .4 .1$ & 15 blue $^{\mathrm{a} / \text { violet }^{\mathrm{b}}}$ & 19 violet ${ }^{a} / y_{\text {ellow }}^{b}$ & 35 brown $^{\mathrm{d}} /$ yellow ${ }^{\mathrm{b}}$ & 54 violet $^{\mathrm{a}} /$ yellow $^{\mathrm{b}}$ \\
\hline F-2B.1.4.2 & 15 blue $^{a} /$ violet $^{b}$ & 19 violet $^{\mathrm{a}} /$ yellow $^{\mathrm{b}}$ & $35 \mathrm{brown}^{\mathrm{d}} / \mathrm{yellow}^{\mathrm{b}}$ & 54 violet $^{\mathrm{a}} / \mathrm{yellow}^{\mathrm{b}}$ \\
\hline $\mathrm{F}-2 \mathrm{~B} \cdot 1.4 .3$ & $-\varsigma$ & $-c$ & $-c$ & $-c^{2}-1$ \\
\hline I-Asp & 15 blue $^{a} /$ violet $^{b}$ & & & \\
\hline L-Glu & & 19 violet $^{\mathrm{a}} /$ yellow $^{\mathrm{b}}$ & & \\
\hline Gly & & & 35 brown $^{\mathrm{a}} /$ yellow ${ }^{\mathrm{b}}$ & \\
\hline Tau & & & & 54 violet $^{a} /$ yellow $^{b}$ \\
\hline
\end{tabular}


Table 2. Qualitative and quantitative DFAA analysis of bioactive samples. No DFAA were detected in the FSW controls within the detection limit of $0.013 \mu \mathrm{M}$. Concentrations of analyzed samples given in footnotes. Asp: aspartic acid; Glu: glutamic acid; Ser:

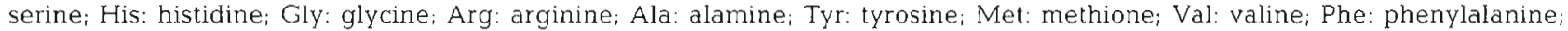

Ile: isoleucine; Leu: leucine; Lys: lysine; Asn: asparagine; Gln: glutamine; Tau: taurine; Trp: tryptophan. nd: not determined

\begin{tabular}{|c|c|c|c|c|c|c|c|}
\hline \multirow{4}{*}{$\begin{array}{l}\text { Amino } \\
\text { acid }\end{array}$} & \multicolumn{5}{|c|}{ Hydroides elegans $\longrightarrow$} & \multirow{2}{*}{\multicolumn{2}{|c|}{$\begin{array}{c}\text { Bugula neritina } \\
\text { Colony }\end{array}$}} \\
\hline & \multirow{3}{*}{\multicolumn{2}{|c|}{$\begin{array}{l}\text { Adult worm homogenate } \\
\text { F-2B.1.4.(1+2) } 0.5 \mathrm{kDa}-\text { filtrate } \\
10^{-6} \mathrm{M} \quad 10^{-6} \mathrm{M}\end{array}$}} & \multirow{3}{*}{$\begin{array}{c}\text { Colony } \\
\text { Conditioned FSW } \\
10^{-6} \mathrm{M}\end{array}$} & \multicolumn{2}{|c|}{ Gametes } & & \\
\hline & & & & Eggs ${ }^{c}$ & Sperm ${ }^{c}$ & Conditioned FSW & HPLC fraction ${ }^{d}$ \\
\hline & & & & $10^{-6} \mathrm{M}$ & $10^{-6} \mathrm{M}$ & $10^{-6} \mathrm{M}$ & $10^{-6} \mathrm{M}$ \\
\hline Asp & 1.12 & 1.35 & 0.34 & 0.25 & 0.56 & 1.33 & 0.92 \\
\hline Glu & 0.76 & 0.82 & 2.87 & 0.57 & 1.52 & 2.00 & 1.60 \\
\hline Ser & 1.3 & 1.35 & 1.93 & 0.28 & 0.43 & 1.16 & 0.21 \\
\hline His & 0.2 & 0.22 & 0.63 & 0.80 & 0.22 & 2.99 & 2.26 \\
\hline Gly & 4.94 & 5.31 & 3.62 & 2.52 & 19.00 & 3.75 & 3.05 \\
\hline Arg & 1.02 & 1.14 & 0.53 & nd & nd & 0.95 & 0.52 \\
\hline Ala & 2.05 & 2.27 & 1.58 & 0.74 & 1.18 & 4.31 & 3.23 \\
\hline Tyr & nd & 0.96 & 0.47 & nd & nd & 0.73 & nd \\
\hline Met & nd & 0.30 & 0.14 & nd & nd & 0.41 & nd \\
\hline Val & nd & 0.87 & 0.41 & nd & nd & 1.58 & nd \\
\hline Phe & nd & 0.92 & 0.27 & nd & nd & 0.62 & nd \\
\hline Ile & nd & 0.72 & 0.17 & nd & nd & 1.05 & nd \\
\hline Leu & nd & 1.40 & 0.42 & 0.19 & 0.19 & 1.73 & nd \\
\hline Lys & nd & 1.11 & nd & 0.19 & 0.46 & 0.55 & nd \\
\hline Asn & 0.43 & 0.53 & 0.57 & 0.31 & 0.32 & 0.46 & 0.26 \\
\hline Gln & 0.86 & 0.97 & 0.38 & 0.29 & 0.29 & 1.26 & 1.00 \\
\hline Tau & 5.62 & 5.98 & 2.97 & 2.40 & 2.14 & 8.12 & 7.54 \\
\hline Trp & nd & 0.17 & nd & nd & nd & nd & $\mathrm{nd}$ \\
\hline
\end{tabular}

fied the separated spots as aspartic acid, glutamic acid, glycine and taurine.

\section{Dissolved free amino acid analysis - bioassays with quantified samples}

In Table 2, the result of qualitative and quantitative DFAA analysis of the isolate, i.e. Fraction F-2B1.4. $(1+2)$ is compared with the corresponding data of the aqueous extract of adult Hydroides elegans homogenate, the male/female germ cells' covering fluid and FSW samples conditioned with live colonies of $H$. elegans and Bugula neritina in the laboratory. No DFAA were determined in the seawater samples taken in close proximity to a $H$. elegans colony in the field (detection limit: $0.013 \mu \mathrm{M}$ ).

An artificially prepared amino acid sample (AAS) was prepared in the same concentration and amino acid composition as quantified in the natural isolate $F$ 2B1.4.(1+2) (Table 2). The AAS was assayed along with the natural isolate and the $0.5 \mathrm{kDa}$ ultrafiltrate of the aqueous extract of adult Hydroides elegans homogenate $(0.5 \mathrm{kDa}$ filtrate) both with antibiotics and without (Fig 9A). After $48 \mathrm{~h}$, no significant difference in

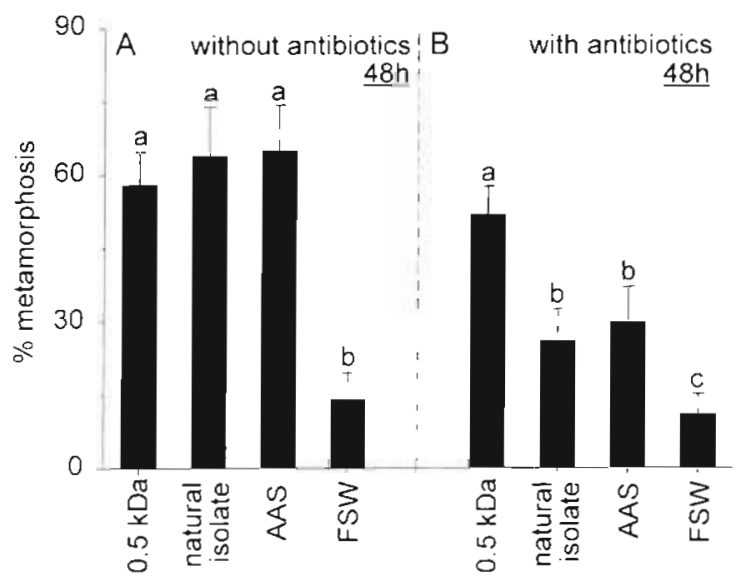

Fig. 9. (A) Mean percentage of larval metamorphosis after $48 \mathrm{~h}$ in response to $0.5 \mathrm{kDa}$ filtrate of the aqueous extract of adult Hydroides elegans homogenate $(0.5 \mathrm{kDa})$, Fraction F2B.1.4.(1+2) (natural isolate) and the artificially prepared amino acid sample (AAS). (A) Without and (B) with antibiotics. One-way ANOVA followed by Tukey's multiple comparisons test $(\alpha=0.05)$ was performed with ranked data of the non-antibiotic and antibiotic treatments separately $(\mathrm{p}<$ $0.0001)$. Data plotted are means $+\mathrm{SD}$ of 5 replicates. Data that are significantly different are indicated by different letters above the bars 
larval metamorphosis was observed among the treatments without antibiotics ( $p>0.62$, Tukey's test). They induced a significantly higher percentage of larval metamorphosis than the FSW control ( $p<0.05$, Tukey's test). In the antibiotic treatment, the $0.5 \mathrm{kDa}$ filtrate induced $52 \%$ of larval metamorphosis, which was significantly higher than the metamorphic rate induced by the natural isolate and the AAS ( $p<0.005$. Tukey's test) and by the FSW control ( $p<0.0001$, Tukey's test). There was no significant difference in percentage of larval metamorphosis between the natural isolate and the AAS ( $p=0.62$, Tukey's test). Statistical analysis by 2 -way ANOVA revealed a significant influence of antibiotics on larval metamorphic rates $(p<0.0001)$. A comparison of larval metamorphic rates of each sample with its antibiotic treatment demonstrated significant differences between the natural isolate and the AAS ( $p$ $<0.01$, Mann-Whitney $U$-test), whereas statistic similarity between the treatments of the $0.5 \mathrm{kDa}$ filtrate of aqueous extract of adult $H$. elegans homogenate was observed ( $p=0.17$, Mann-Whitney $U$-test).

\section{DISCUSSION}

Early investigations in our research group into factors other than natural biofilm that induce larval attachment and metamorphosis of Hydroides elegans have indicated chemical inducers present in the leachate of Bugula neritina (Bryan et al. 1998) and the aqueous extract of the homogenate of conspecific adults (Bryan et al. 1997). In laboratory bioassays, these crude samples induced competent larvae of $H$. elegans to attach and metamorphose into fully developed juveniles after $48 \mathrm{~h}$. Partial purification of these samples revealed the molecular weight of inductive compounds in both samples to be lower than $10 \mathrm{kDa}$ (Bryan et al. 1997, 1998).

In the present study, we elaborated a chromatographic separation procedure in order to verify the existence of chemical larval metamorphic inducers for Hydroides elegans in these samples. The separation was guided by an established and generally accepted bioassay procedure modified from Maki et al. (1988). By conducting sample preparation methods such as solid-phase extraction and subsequent ultrafiltration, we separated polar water-soluble, bioactive compounds with a molecular weight lower than $0.5 \mathrm{kDa}$. Through a series of different chromatographic procedures we ultimately purified a sample fraction (isolate) that induced $64 \%$ of larval metamorphosis in the bioassay (Fig. 9A). This metamorphic response was similar to bioassay results with the aqueous extract of adult $H$. elegans homogenate at the most effective concentration of $0.1 \mathrm{mg}$ lyophilisate $\mathrm{ml}^{-1} \mathrm{FSW}$ (58\%, Fig. 9A).
Owing to identical dilution factors, this result suggested that bioactive compounds were nearly completely enriched in the final isolate F-2B.1.4.(1+2) (Fig. 8B). Variances in metamorphic rates of bioactive fractions throughout the HPLC analysis were presumably caused by differences in larval responsiveness of different batches of larvae.

With reference to our chromatographic results, we hypothesized that polar low molecular weight compounds such as sugars, amino acids or short oligopeptides constituted the isolate. Chemical elucidation of the isolate was finally achieved by further TLC analysis. Specific postchromatographic derivatization reactions with the concentrated isolate indicated compounds with primary amino functions and excluded the presence of unsaturated carbon and intramolecular amide bonds. This result suggested that the bioactive isolate solely consisted of primary amines and/or amino acids. This indication was verified by TLC comparison of the isolate with synthetic amino acids. As shown in Table 1, the 4 amino acids glycine, glutamic acid, aspartic acid, and taurine were definitely identified. Quantitation of these DFAA with the more sensitive OPA method revealed additional DFAA in the isolate. Table 2 summarizes the qualitative and quantitative amino acid composition of the isolate and the aqueous extract of adult Hydroides elegans homogenate. A comparison indicates that the elaborated separation procedure selectively enriched polar and charged DFAA, excluding those with aromatic and nonpolar, aliphatic side chains

The larval metamorphic response to the AAS was very similar to the results for the natural isolate, i.e. Fraction F-2B.1.4.(1+2) (Fig. 9A). Obviously, the metamorphosis inductive activity in the AAS was exclusively determined by the DFAA provided (Table 2). Owing to the same percentage of larval metamorphosis, the overall activity in the $0.5 \mathrm{kDa}$ filtrate of adult Hydroides elegans homogenate was apparently limited to the amino acid composition quantified in the natural isolate (Fig. 8B). According to this result, tyrosine, methionine, valine, phenylalanine, isoleucine, leucine, lysine and tryptophan (all of them characterized by aromatic and nonpolar, aliphatic side chains) did not contribute to the bioactivity in assays with the $0.5 \mathrm{kDa}$ filtrate of adult $H$. elegans homogenate.

The bioassay performed in this study was specifically designed to avoid the development of a potential bioactive microbial film in the assay vessels. Sterile petri dishes were used and samples under investigation were filter sterilized $(0.22 \mu \mathrm{m})$ prior to each bioassay. Other bioassay attempts inevitably resulted in the buildup of a visible bioactive organic film in the assay dish within $24 \mathrm{~h}$ (authors' obs.). These attempts in cluded established procedures, e.g. bioassaying larvae 
along with adult specimens or dissected parts as well as smearing crude animal homogenate onto microscope slides. These techniques are not applicable for a selective investigation of potential chemical larval metamorphic inducers, particularly if larvae settle in response to bio-organic films, as is the case with Hydroides elegans.

Despite the performance of mostly sterile bioassays, we could not entirely rule out the potential buildup of a bacteria film in assay dishes and its influence on larval settlement rates. Provided that there is a possibility that bacteria may be inoculated into assay dishes along with larvae, we assumed that an addition of antibiotics significantly diminished larval metamorphic rates. Therefore, experiments with bioactive samples were analogously performed with antibiotics. In our experiments, antibiotics had no significant effect on percentage of larval metamorphosis in assays with $0.5 \mathrm{kDa}$ filtrate of adult $H$. elegans homogenate (see Fig. 9A,B), whereas they lowered the metamorphic rate in treatments with the natural isolate and the AAS about $30 \%$. Obviously, these samples were still bioactive in the presence of antibiotics. The apparent influence of antibiotics on a presumptive larva-bacteria film-DFAA interaction is the topic of a further investigation (Beckmann et al. unpubl.).

As outlined above, Bryan et al. (1997) hypothesized the aqueous extract of adult Hydroides elegans homogenate to be a natural source of conspecific larval metamorphic inducer. Evidently, the homogenate does not naturally occur in this state. It seems likely that a variety of proteinacious amino acids is released as a consequence of tissue homogenization. The identified DFAA may therefore only be ecologically relevant as a metamorphic cue for larvae of $H$. elegans when they are naturally released in sufficient concentrations. There was no significant larval metamorphic response to a seawater sample gained in close proximity to an aggregation of $H$. elegans in the natural environment. This sample did not contain detectable amounts of DFAA. However, our results demonstrated biological activity in seawater conditioned with a living $H$. elegans colony cluster in laboratory conditions. The metamorphic larval response to this sample was almost the same as to $0.5 \mathrm{kDa}$ filtrate and the isolate of the aqueous extract of adult $H$. elegans homogenate (Figs. 1B \& 9A). Compared to the isolate, the conditioned seawater contained all DFAA in nearly the same concentration range (Table 2). Spawning individuals likely release plumes of DFAA into the surrounding environment as we also determined amino acids in the germ cells' encasing body fluid (Table 2). Possibly, additional sources naturally associated with $H$. elegans colonies contribute to the net release of amino acids. Hence, fecal pellets in the gray deposit embedded in the inter- stices of tubes in the colony may provide a reservoir. Moreover, we assume that amino acids are released as metabolites of phytoplankton (Hellebust 1974) and zooplankton (Webb \& Johannes 1967) attached to the colony. The source of DFAA is therefore obviously not restricted to individuals of $H$. elegans alone

The results of laboratory bioassays with $1 / 10$ diluted leachate of Bugula neritina colonies were very similar to those with the $0.5 \mathrm{kDa}$ filtrate and the isolate of adult Hydroides elegans homogenate (Figs. 1B \& 9A). Therefore, we hypothesized the leachate's bioactivity to be based on DFAA as well. The analysis revealed a very similar amino acid composition in 1/10 diluted leachate of $B$. neritina, in $0.5 \mathrm{kDa}$ filtrate of adult $H$. elegans homogenate at $0.1 \mathrm{mg}$ lyophilisate $\mathrm{ml}^{-1} \mathrm{FSW}$ and in FSW conditioned with an $H$. elegans colony (Table 2). The biological activity was restricted to a HPLC fraction with chromatographic retention values like those of Fraction F-2B.1 (Fig. 6A) and revealed an identical amino acid composition in similar concentrations to those of Fraction F-2B.1.4.(1+2) (Table 2).

Our findings confirm those of Bryan et al. (1998) in the sense that leachate of Bugula neritina contains a bioactive chemical inducer for the induction of larval attachment and metamorphosis of Hydroides elegans. However, we found that bioactive metabolites from leachate of $B$. neritina were not bound to amberlite $\mathrm{XAD}-2$ resin, a non-polar adsorbent. In contrast to their results, this indicated a hydrophilic nature of these compounds. Repeating the flash-chromatographic step through a column packed with XAD-2, we determined only the aqueous eluent to be bioactive rather than the methanol eluent containing compounds bound on the stationary phase (Harder \& Qian unpubl. results). In analogy with Bryan et al. (1998), we determined the methanol extract of freeze-dried leachate to be bioactive as well. However, when we redissolved the methanol extraction residue in Milli-Q water, we determined a distinctly higher metamorphic response in comparison to the bioactivity of compounds present in the methanol extract. In both samples, the biological activity was caused by DFAA, as proven by bioassayguided HPLC analysis (Harder \& Qian unpubl. results). According to our results, we therefore conclude that the larval metamorphic response determined in the methanol extract of leachate of $B$. neritina and in the XAD-2 methanol eluent by Bryan et al. (1998) was caused by residual amino acids, finally enriched to efficacious concentrations. Provided that lipophilic compounds in the leachate of $B$. neritina display inducers for larval attachment and metamorphosis, we should have determined a bioactive HPLC fraction with certainly longer retention values than we actually observed. In conclusion, we cannot confirm that inductive compounds originating from $B$. neritina and $H$. 
elegans have a fundamentally different structure, as proposed by Bryan et al. (1998).

Bryan et al. (1997) and Bryan et al. (1998) hypothesized that the aqueous homogenate of Hydroides elegans adults and the exudate of Bugula neritina colonies contain a chemical inducer for larval attachment and metamorphosis of $H$. elegans. In this study, we found that a composition of polar and aliphatic DFAA (see Table 2) constituted the biological activity of these samples in laboratory assays. However, our results highlight 2 important issues which question the ecological significance of the identified DFAA as natural chemical larval metamorphic inducers for $H$. elegans. (1) Colonies of $H$. elegans and $B$. neritina may not be the sole sources of amino acids in the natural environment. It seems very reasonable to suspect that amino acids from every potential source will trigger larval attachment and metamorphosis in laboratory assays as long as polar, aliphatic amino acids are provided in micromolar concentrations. (2) Detectable amounts of DFAA are absent in close proximity to aggregations of $H$. elegans in the marine environment.

In order to determine if DFAA act as a chemical cue for larval attachment and metamorphosis in the natural environment it is very important to know the mode of action of the complex of polar aliphatic amino acids on competent larvae of Hydroides elegans. The results of a detailed analysis of the mechanism of action of DFAA on larvae of $H$. elegans will be presented in a subsequent publication (Beckmann et al. unpubl.).

Acknowledgements. The authors thank M. Beckmann for his valuable comments and contribution to this work as well as for his support in qualitative amino acid analysis. We also thank S. C. K. Lau for comments on the manuscript, L. Soo for technical support, A. Poon for assistance in algal culture, S. C. K. Lau and J. W. Qiu for statistical consultation, T T. LePhung for her assistance in technical writing, and 4 reviewers for their valuable comments and suggestions on the manuscript. This study was supported by a RGC grant (HKUST 651/96M) to P.Y.Q.

\section{LITERATURE CITED}

Bryan PJ, Qian PY, Kreider JL, Chia FS (1997) Induction of larval settlement by pharmacological and conspecific associated compounds in the serpulid polychaete Hydroides elegans. Mar Ecol Prog Ser 146:81-90

Bryan PJ, Kreider JL, Qian PY (1998) Settlement of the serpulid polychaete Hydroides elegans (Haswell) on the arborescent bryozoan Bugula neritina (L.): evidence of a chemically mediated relationship. J Exp Mar Biol Ecol 220:171-190

Conover WJ, Iman L (1981) Rank transformations as a bridge between parametric and nonparametric statistics. Am Stat $35: 124-129$
Crisp DJ (1974) Factors influencing the settlement of marine invertebrate larvae. In: Grant PT, Mackie AM (eds) Chemoreception in marine organisms. Academic Press, London, p 177-245

Hadfield MG, Unabia CC, Smith CM, Michael TM (1994) Settlement preferences of the ubiquitious fouler Hydroides elegans. In: Thompson MF, Nagabhushanam R, Sarojni R, Fingerman $M$ (eds) Recent developments in biofouling control. AA Balkema, Rotterdam, p 65-74

Hellebust JA (1974) Extracellular products. In: Stewart ND (ed) Algal physiology and biochemistry. University of California, Berkley, p 838-863

Jork H, Funk W, Fischer W, Wimmer H (1990) Thin-layer chromatography. Reagents and detection methods, Vol 1a VCH Verlagsgesellschaft, Weinheim

Lau SCK, Qian PY (1997) Phlorotannins and related compounds as larval settlement inhibitors of a tube-building polychaete Hydroides elegans. Mar Ecol Prog Ser 159; $219-227$

LeTourneux F, Bourget E (1988) Importance of physical and biological settlement cues used at different spatial scales by the larvae of Semibalanus balanoides. Mar Biol 97 : $57-66$

Lindroth P, Mopper K (1979) High-performance liquid chromatographic determination of subpicomole amounts of amino acids by precolumn fluorescence derivatization with o-phtaldialdehyde. Anal Chem 51:1667-1674

Maki JS, Rittschof D. Schmidt AR, Snyder AG, Mitchell R (1988) Factors controlling attachment of bryozoan larvae: a comparison of bacterial films and unfilmed surfaces. Biol Bull 177:295-302

Pawlik JR (1992) Chemical ecology of the settlement of benthic marine invertebrates. Oceanogr Mar Biol Annu Rev 30:273-335

Pechenik JA, Qian PY (1998) Onset and maintenance of metamorphic competence in the marine polychaete Hydroides elegans in response to three chemical cues. J Exp Mar Biol Ecol 226(1):51-74

Qian PY, Pechenik JA (1998) Effects of larval starvation and delayed metamorphosis on juvenile survival and growth of the tube-dwelling polychaete Hydroides elegans (Haswell). J Exp Mar Biol Ecol 227(2):169-185

Qiu JW, Qian PY (1997) Combined effects of salinity, temperature and food on early development of the polychaete Hydroides elegans. Mar Ecol Prog Ser 152:79-88

Rodriguez SR, Ojeda FP, Inestrosa C (1993) Settlement of benthic marine invertebrates. Mar Ecol Prog Ser 97 193-207

Shapiro SS, Wilk MB (1965) An analysis of variance test for normality (complete samples). Biometrika 52:591-611

Stahl E (1969) Thin-layer chromatography. A laboratory handbook. Springer-Verlag, Berlin

Walters LJ, Hadfield MG, del Carmen KA (1997) The importance of larval choice and hydrodynamics in creating aggregations of Hydroides elegans (Polychaeta: Serpulidae). Invertebr Biol 116:102-114

Webb KL, Johannes RE (1967) Studies of the release of dissolved free amino acids by marine zoaplankton. Limnol Oceanogr 12:376-382

Wisely B (1958) The development and settling of a serpulid worm, Hydroides norvegica Gunnerus (Polychaeta). Aust J Mar Freshw Res 9:351-361

Zar JH (1996) Biostatistical analysis, 3rd edn. Prentice Hall International, Inc, Upper Saddle River, NJ

Submitted: February 9, 1998; Accepted: November 18, 1998

Proofs received from author(s): March 3, 1999 